\title{
Monitoring of gas station attendants exposure to benzene, toluene, xylene (BTX) using three-color chromosome painting
}

Fábio Santiago ${ }^{1,2,3}$, Gilda Alves ${ }^{2,3,7^{*}}$, Ubirani Barros Otero ${ }^{4}$, Marianne Medeiros Tabalipa ${ }^{4}$, Luciano Rios Scherrer ${ }^{5}$, Nadezda Kosyakova ${ }^{6}$, Maria Helena Ornellas ${ }^{1,2}$ and Thomas Liehr ${ }^{6}$

\begin{abstract}
Background: Chronic exposure of BTX (benzene, toluene, xylene) may lead to progressive degeneration of bone marrow, aplastic anemia and/or leukemia. In Brazil there is no self-service fuel in gas stations and attendants fill the fuel themselves. Due to this they are chronically exposed to high concentration of BTX. Occupational exposure to benzene has been associated with increased chromosomal aberrations in peripheral blood lymphocytes. Fluorescence in situ hybridization (FISH) using whole chromosome painting (wcp) probes allows the rapid detection of chromosomal aberration. In the present study three-color wcp probes for chromosomes 1, 2 and 4 were used for monitoring 60 gas station attendants.

Results: Blood tests were done and interviews were conducted for each worker. For searching for possible associations between the clinical characteristics and the frequency of chromosomal aberrations the workers were divided into two groups ( $\leq 10$ chromosomal abnormalities per 1,000 metaphases and $>10$ chromosomal abnormalities per 1,000 metaphases).The studied workers had a low median age (36 year), albeit long period of BTX exposure (median was 16 years). Low prevalence of smoking and moderate consumption of alcoholic beverages were found in this population. The cytogenetic analysis showed $16.6 \%(10 / 60)$ of workers with a high frequency of chromosomal abnormalities (>10 chromosomal abnormalities per 1,000 metaphases). Translocations were the most frequently observed chromosome aberration. The statistical analysis revealed highly significant differences in skin color $(p=0.002)$ and a weak significant differences in gender $(p=0.052)$ distribution between the two groups.

Conclusion: $16.6 \%$ of the studied population showed elevated frequencies of chromosomal abnormalities, which is highly likely to be correlated with their exposure to BTX during their work. Therefore, further studies are needed for better characterize the work associated damage of the genome in gas station workers. It is necessary to better understand the risks that these workers are exposed, so that we can be effective in preventing diseases and maintaining the health of these workers and possibly the offspring.
\end{abstract}

Keywords: Benzene, Toluene, Xylene, Monitoring, Cytogenetic, Painting, Chromosome

\footnotetext{
*Correspondence: gbrown@inca.gov.br

2Programa de Pós-Graduação em Ciências Médicas, Faculdade de Ciências

Médicas, Universidade do Estado do Rio de Janeiro, Rio de Janeiro, Brasil

${ }^{3}$ Laboratório de Genética Aplicada, Serviço de Hematologia, Instituto

Nacional de Câncer, Rio de Janeiro, Brasil

Full list of author information is available at the end of the article
} 


\section{Background}

In contrast to many developed countries, there are no self service fuel in gas stations in Brazil. Filling in fuel depends on attendants who are chronically exposed to BTX (benzene, toluene and xylene) during the work time. It is well known that benzene induces myelotoxicity in humans; the role of xylene and toluene is still unclear, thus, here we concentrate on the best studied substance among those three, benzene. It causes a variety of hematological disorders including aplastic anemia, myelodysplastic syndrome, and acute myelogeneous leukemia (AML) [1-4]. Benzene is metabolized in the liver to its primary metabolite phenol by cytochrome P4502E1 (CYP2E1) through the benzene oxide intermediate, and is subsequently metabolized by CYP2E1 to hydroquinone $(\mathrm{HQ})[5,6]$. HQ is transported to the bone marrow and oxidized to benzochinones, which eventually releases reactive oxygen species (ROS) damaging hematopoietic cells [5,7].

Many studies have been carried out to determine the hematological alterations and chromosomal aberrations (CA) in benzene exposed workers [8-11]. Reported genetic damages caused by benzene include sister chromatid exchange, DNA cross-linking, DNA adduct formation, and impairment of DNA repair mechanisms [12]. Other studies reported increased levels of chromosomal anomalies such as aneuploidies including monosomy of chromosomes 5 and 7 and trisomies of chromosomes 8 and 21 , in the blood lymphocytes of apparently healthy Chinese workers exposed to high levels of benzene (median: $31 \mathrm{ppm}$, range: 1.6-328.5 ppm). It is well known that these kinds of alterations are also commonly found in leukemia and myelodysplastic syndrome $[7,10,13]$. Thus, chromosomal aberrations may be a precursor of future leukemia risk and other cancers. Additional studies have further strengthened the association between increased levels of $\mathrm{CA}$ in human lymphocytes and future cancer incidence and mortality $[13,14]$.

Fluorescence in situ hybridization (FISH) using whole chromosome painting (wcp) libraries opened new insights in studying the CA in people exposed to mutagens and in delimiting individuals at risk [15]. This approach allows the rapid detection of translocations and other cytogenetic alterations, enabling new possibilities of cytogenetic dosimetry. This kind of test can also be used to address the chromosomal rearrangements detectable in individuals exposed to benzene and delimiting their individual cancer risk $[1,15]$.

The aim of this study was to describe the cytogenetic changes on chromosomes 1,2 and 4 in gas station attendants from Rio de Janeiro, Brazil, that had occupational exposition to BTX. The obtained results were used as an indicator for chromosomal damage as a whole, which happened in this population due to their work exposure.

\section{Results}

\section{Health report}

The gas station attendants routinely work for 6 days a week, during 8 hours or more per day. As it can be deduced from Table 1 the median time of employment in this activity was 16 years and their median age was 36 years. A low prevalence of smoking (15\%) and a moderate consumption of alcoholic beverage (65\%) were reported. No illicit drugs consumption (marijuana, cocaine and ecstasy) and no high consume of alcoholic beverages were described.

In the medical history of workers vision impairment $(22.6 \%)$ was the complaint most frequently reported, followed by osteoarticular*a ${ }^{* a}$ (18.5\%), cardiovascular (16.0\%) and respiratory tract diseases (12.6\%). Hematological diseases $(1.8 \%)$ were scarce, and no neoplasic diseases were reported.

\section{Cytogenetic data}

A high frequency of CA ( $>10$ chromosomal abnormalities per 1,000 metaphases) was found in $16.6 \%(10 / 60)$, whereas $83.4 \%$ (50/60) of workers showed no aberrations

Table 1 Biometrics data (clinical and demographic) of gas station attendants

\begin{tabular}{|c|c|c|}
\hline Biometrics data & \multicolumn{2}{|c|}{ Results } \\
\hline \multicolumn{3}{|l|}{ Gender } \\
\hline Men & \multicolumn{2}{|c|}{$50(83.3 \%)$} \\
\hline Women & \multicolumn{2}{|c|}{$10(16.7 \%)$} \\
\hline Age (years) & \multicolumn{2}{|c|}{$36( \pm 13.5)$} \\
\hline Duration of exposure (years) & \multicolumn{2}{|c|}{$16( \pm 11.8)$} \\
\hline Smokers & \multicolumn{2}{|c|}{$9(15 \%)$} \\
\hline Ex-smokers & \multicolumn{2}{|c|}{$9(15 \%)$} \\
\hline Illicit drug consumption & \multicolumn{2}{|c|}{$0(0 \%)$} \\
\hline Drinking & \multicolumn{2}{|c|}{$39(65 \%)$} \\
\hline Ex-drinking & \multicolumn{2}{|c|}{$3(5 \%)$} \\
\hline Blood test & Men & Women \\
\hline Erythrocytes (million/ $\mu \mathrm{L}$ ) & $4.9( \pm 0.32)$ & $4.5( \pm 0.26)$ \\
\hline Hemoglobin & $14.4( \pm 1.14)$ & $12.7( \pm 1.07)$ \\
\hline Hematocrit (\%) & $42.3( \pm 2.84)$ & $37.4( \pm 2.91)$ \\
\hline Mean corpuscular volume (fL) & $84.9( \pm 4.55)$ & $84.9( \pm 4.26)$ \\
\hline Leukocytes(/uL) & \multicolumn{2}{|c|}{$7025( \pm 1677.6)$} \\
\hline Neutrophils(\%) & \multicolumn{2}{|c|}{$57( \pm 9.26)$} \\
\hline Typical lymphocytes & \multicolumn{2}{|c|}{$33( \pm 8.39)$} \\
\hline Basophils (\%) & \multicolumn{2}{|c|}{$0.4( \pm 0.25)$} \\
\hline Eosinophils (\%) & \multicolumn{2}{|c|}{$2.5( \pm 2.52)$} \\
\hline Monocytes (\%) & \multicolumn{2}{|c|}{$7.1( \pm 1.76)$} \\
\hline Platelets (mil/ $\mu \mathrm{L})$ & \multicolumn{2}{|c|}{$230( \pm 54.05)$} \\
\hline Gamma-GT (U/L) & \multicolumn{2}{|c|}{$32( \pm 44.2)$} \\
\hline
\end{tabular}

Gamma GT- Gamma glutamyl transpeptidase. 
or less than 10 chromosomal abnormalities per 1,000 metaphases. Table 2 shows the CAs found on molecular cytogenetic analysis and Figure 1 shows an example of an abnormal metaphase.

A compared to normal controls (see Discussion) elevated frequency of CAs (9.3 per 1,000 metaphases analyzed) was found in the gas station workers population. Among the total CAs the translocations were most frequently found (43.6\%), followed by deletions (23.7\%); monosomies (10.9\%); chromosomal breaks (12.7\%); chromosomal fragments (7.3\%) and trisomies (1.8\%).

Translocations of chromosome 2 were responsible for $20 \%$ of total CAs, followed by translocation involving chromosome 1 (18.2\%) and gross deletions within chromosome 2 (9.1\%). Chromosome 1 showed the highest percentage of CAs (41.8\%) that corresponded to: translocations (18.2\%), chromosome breakage (7.2\%), deletions

Table 2 Chromosomal abnormalities of gas station workers

\begin{tabular}{|c|c|}
\hline Number & Chromosomal abnormalities \\
\hline 1 & chrb(1); del(1),del(2);chrb(1);t(2;?);t(2,?) \\
\hline 2 & chrb(1);chrb(4) \\
\hline 3 & $\mathrm{t}(1 ; 2 ; ?), \mathrm{t}(2 ; ?), \mathrm{t}(4, ?)$ \\
\hline 4 & $\mathrm{t}(1 ; ?), \operatorname{chrb}(1) ; \mathrm{t}(2 ; ?)$ \\
\hline 5 & $\operatorname{ace}(1)$ \\
\hline 6 & $-1, \operatorname{ace}(1) ; \operatorname{del}(4 p) ; t(1 ; ?)$ \\
\hline 7 & $\mathrm{t}(2, ?)$ \\
\hline 8 & $\mathrm{t}(1 ; ?), \mathrm{t}(2 ; ?) ; \mathrm{del}(1), \mathrm{del}(4)$ \\
\hline 9 & $\mathrm{t}(1 ; 2)$ \\
\hline 10 & $\mathrm{t}(1 ; ?)$ \\
\hline 11 & $\operatorname{der}(1), \mathrm{t}(1 ; 2)$ \\
\hline 12 & $\operatorname{del}(2) ; t(1 ; ?) ; t(4 ; ?) ; \operatorname{ace}(4)$ \\
\hline 13 & +4 \\
\hline 14 & $\operatorname{del}(2)$ \\
\hline 15 & del(4) \\
\hline 16 & $\operatorname{del}(2)$ \\
\hline 17 & $\operatorname{del}(1), \operatorname{del}(2) ;-4$ \\
\hline 18 & $-4, \operatorname{ace}(4)$ \\
\hline 19 & $\mathrm{t}(2 ; ?)$ \\
\hline 20 & -4 \\
\hline 21 & $\operatorname{chrb}(4)$ \\
\hline 22 & $t(1 ; ?)$ \\
\hline 23 & $\operatorname{del}(4)$ \\
\hline 24 & -1 \\
\hline 25 & chrb(2) \\
\hline 26 & -1 \\
\hline 27 & $t(4 ; ?)$ \\
\hline 28 & $t(1 ; ?)$ \\
\hline 29 & $\mathrm{t}(2 ; ?)$ \\
\hline
\end{tabular}

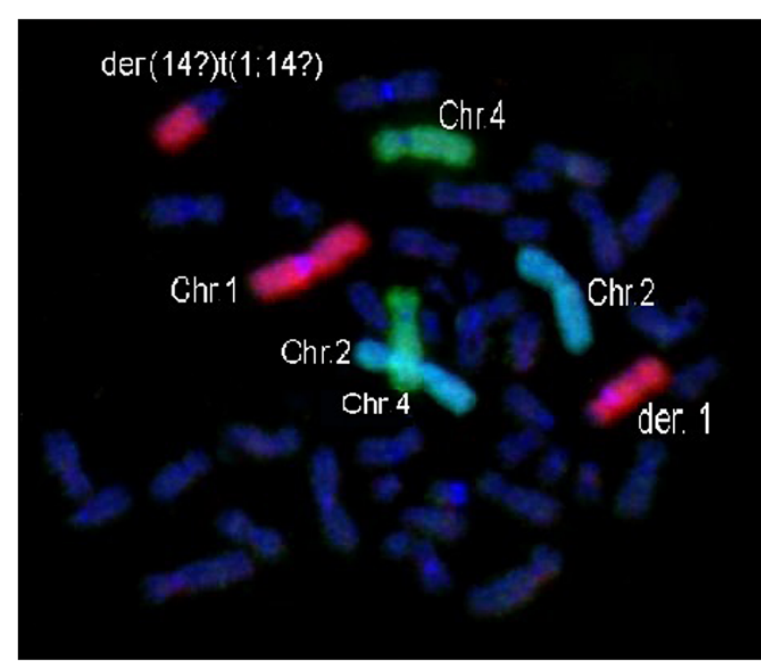

Figure 1 The figure shows a translocation of chromosome 1. The home made probes were conjugated with spectrum Orange for painting the chromosome 1 (red in the picture); spectrum FITC for painting the chromosome 2 (light blue in the picture) and spectrum DEAC for painting the chromosome 4 (green in the picture). DAPI was used with anti-fade solution (dark blue in the picture).

(7.2\%), monosomies (5.4\%), and formation of chromosome fragments (3.6\%). Chromosome 4 had the lowest percentage of CAs observed (27.3\%). Among the CAs of chromosome 4 the most common were deletions (7.2\%), followed by translocations (5.4\%), monosomies (5.4\%), chromosome breaks $(3.6 \%)$, chromosome fragments $(3.6 \%)$ and trisomies $(1.8 \%)$.

The number of translocations was compared to other chromosomal aberrations that were found. Table 3 shows that significantly differences were present, pointing that monosomies $(p=0.022)$, trisomies $(p=0.00)$ and chromosomal fragments $(\mathrm{p}=0.007)$ were less frequent than translocations in chromosome 1 . In Table 4 the same analysis was done for chromosome 1 and 2. The translocation of chromossome 2 was the most frequent aberration seen in this chromosome. The overall-involvement of translocations in rearrangements did not show any significant differences for the number of translocations of chromosome 4 compared to the other chromosomal aberrations.

\section{Association between the cytogenetic results and clinical and demographic data}

For possible associations between the clinical characteristics and the frequency of CAs the subjects were divided into two groups ( $\leq 10 \mathrm{CAs}$ per 1,000 metaphases $=$ group 1 , and $>10$ CAs per 1,000 metaphases = group 2). The statistical analysis revealed highly significant differences in skin color distribution between the groups $(p=0.002)$. Similarly, we found, when statistical analysis were done, differences only concerning blacks and whites between the two groups $(\mathrm{p}<0.01, \mathrm{OR}=9.02$ and $95 \% \mathrm{CI}[1.54$ to 
Table 3 Statistical analysis between translocations and others chromosomal abnormalities of chromosomes 1, 2 and 4

\begin{tabular}{lcc}
\hline & Number of chromosomal aberrations & P-valor \\
\hline Translocation & 24 & $\begin{array}{c}\text { Aberration } \\
\text { compared }\end{array}$ \\
$\begin{array}{l}\text { Chromosome } \\
\text { breakage }\end{array}$ & 7 & 0.000 \\
$\begin{array}{l}\text { Chromosome } \\
\text { fragment }\end{array}$ & 4 & 0.000 \\
$\begin{array}{l}\text { Deletion } \\
\text { Monosomy }\end{array}$ & 13 & 0.026 \\
Trisomy & 6 & 0.000 \\
\hline
\end{tabular}

97.77]). It was observed that blacks have a lower number of CA than whites. Also we observed on the gender analyze that $88 \%$ of male workers were in group 1 and $12 \%$ in group 2 , while it were $60 \%$ of female workers in the group 1 and $40 \%$ in group 2 .The statistical analysis revealed weak significant differences in gender distribution between the two groups ( $\mathrm{p}=0.052, \mathrm{OR}=4.71$ and $95 \% \mathrm{CI}$ [0.76 to 28.05]).

To assess whether the frequency of CAs has association on hematological and biochemical parameters Table 5 was established. No significant associations were found between frequency of chromosomal aberration and whole blood cell count (WBC), red blood cell count $(\mathrm{RBC})$, Gamma-glutamyltransferase $(\mathrm{p}>0.05)$ and

Table 4 Statistical analysis between translocations and others chromosomal abnormalities of chromosome 1 and 2

\begin{tabular}{|c|c|c|}
\hline & Number of chromosomal aberrations & P-valor \\
\hline \multicolumn{3}{|c|}{ Chromosome 1} \\
\hline Translocation & 10 & $\begin{array}{l}\text { Aberration } \\
\text { compared }\end{array}$ \\
\hline $\begin{array}{l}\text { Chromosome } \\
\text { breakage }\end{array}$ & 4 & 0.055 \\
\hline $\begin{array}{l}\text { Chromosome } \\
\text { fragment }\end{array}$ & 2 & 0.007 \\
\hline Deletion & 4 & 0.055 \\
\hline Monosomy & 3 & 0.022 \\
\hline Trisomy & 0 & 0.000 \\
\hline \multicolumn{3}{|c|}{ Chromosome 2} \\
\hline Translocation & 11 & $\begin{array}{l}\text { Aberration } \\
\text { compared }\end{array}$ \\
\hline $\begin{array}{l}\text { Chromosome } \\
\text { breakage }\end{array}$ & 1 & 0.000 \\
\hline $\begin{array}{l}\text { Chromosome } \\
\text { fragment }\end{array}$ & 0 & 0.000 \\
\hline Deletion & 5 & 0.039 \\
\hline Monosomy & 0 & 0.000 \\
\hline Trisomy & 0 & 0.000 \\
\hline
\end{tabular}

platelets count $(\mathrm{p}=0.059)$, however for the latter $\mathrm{p}$-value was borderline.

\section{Discussion}

In the present study, the frequency of CAs in peripheral blood lymphocytes of Brazilian gas station workers was used as an effect biomarker of BTX exposure. The chromosomes pairs 1, 2 and 4 represent together $21.87 \%$ of human genome. Thus they were chosen for the cytogenetic paint analysis as representatives of the entire human genome as previously described by Verdorfer and colleagues [15].

A questionnaire analysis showed a population with a low median age, albeit with long period of exposure. We did not detect inappropriate health behaviors on life style questions. The self-reported medical history showed that the main health problems were related to acute symptoms; reported sight changes appeared to be mainly associated with direct irritant action of fuel vapor in eyes (no masks are used). Osteoarticular diseases were most likely due to the long period of time in physical labor. Hematological and neoplasic diseases were rarely/not reported by workers, which was most likely due to the quiet character of the natural history of these diseases and the fact that they lead quickly to absence from work. Also they are late manifesting diseases, which might not be present in the on average young population studied.

It should be remembered that fuel volatile fraction contains chemicals other than BTX that may act as aneugens or clastogens. It is likely that the workers in this study were exposed simultaneously to several other complex chemicals. However, considering the different behaviors of environment chemicals once released, the significant relationship observed with respect to BTX concentration, indicates a specific role for BTX, mainly for the benzene, in this association $[9,16]$.

Several studies examined cytogenetic endpoints in subjects exposed to petroleum fuels, auto exhaust, or other organic solvents $[1,10,17-23]$. The benzene exposure has been strongly associated with increased chromosomal abnormalities in the lymphocytes in individuals without diseases [22]. Verdorfer and colleagues analyzed with same technique different groups of individuals with different types of exposures [15]. In our study the workers had a higher frequency of chromosomal abnormalities when compared with Verdorfer groups (control group, military occupied in nuclear area and radiology workers) [15].

In the present search were found 10/60 of workers with high number of chromosome abnormalities (all workers with $\geq 20$ abnormalities per 1,000 metaphase). It is worth to note that in a normal control group only $4 /$ 60 individuals with high number of chromosome abnormalities could be expected ( $\geq 20$ abnormalities per 1,000 metaphase) [15]. 


\begin{tabular}{|c|c|c|c|}
\hline Biometrics data & $\begin{array}{c}\leq 10 \text { chromosomal abnormalities } \\
\text { per } 1000 \text { metaphases }\end{array}$ & $\begin{array}{c}>10 \text { chromosomal abnormalities } \\
\text { per } 1000 \text { metaphases }\end{array}$ & $\mathrm{p}$-value \\
\hline Gender & & & 0.052 \\
\hline Women & 6 & 4 & \\
\hline Men & 44 & 6 & \\
\hline Age (year) & $34.00( \pm 13.73)$ & $42.00( \pm 12.51)$ & 0.177 \\
\hline Time of employment (year) & $12.50( \pm 12.53)$ & $18.00( \pm 8.41)$ & 0.433 \\
\hline Skin color & & & 0.002 \\
\hline Black & 33 & 2 & \\
\hline White & 14 & 8 & \\
\hline Native American & 2 & - & \\
\hline Asian & 1 & - & \\
\hline Platelets (mil/ $\mu \mathrm{L}$ ) & $231.50( \pm 52.41)$ & $195.0( \pm 61.82)$ & 0.059 \\
\hline Gamma-GT (U/L) & $32.0( \pm 48.47)$ & $32.5( \pm 12.58)$ & 0.944 \\
\hline Leukocytes $(/ \mu \mathrm{L}$ & $7020( \pm 172)$ & $6930( \pm 151)$ & 0.835 \\
\hline Neutrophils (\%) & $56.58( \pm 9.66)$ & $57.00( \pm 5.48)$ & 1.000 \\
\hline Eosinophils (\%) & $2.80( \pm 2.65)$ & $1.84( \pm 1.49)$ & 0.312 \\
\hline Basophils (\%) & $0.35( \pm 0.25)$ & $0.27( \pm 0.27)$ & 0.585 \\
\hline Typical lymphocytes (\%) & $33.20( \pm 8.94)$ & $31.20( \pm 4.89)$ & 0.565 \\
\hline Monocytes (\%) & $7.10( \pm 1.84)$ & $7.28( \pm 1.43)$ & 0.866 \\
\hline \multicolumn{4}{|l|}{ Women } \\
\hline Erythrocytes (million/ $\mu \mathrm{L}$ ) & $4.48( \pm 0.22)$ & $4.51( \pm 0.35)$ & 0.521 \\
\hline Hemoglobin & $13.15( \pm 0.9)$ & $12.30( \pm 1.44)$ & 0.669 \\
\hline Hematocrit (\%) & $38.80( \pm 3.01)$ & $36.00( \pm 3.11)$ & 0.915 \\
\hline Mean corpuscular volume (fL) & $84.45( \pm 4.17)$ & $84.90( \pm 4.88)$ & 0.915 \\
\hline \multicolumn{4}{|l|}{ Men } \\
\hline Erythrocytes (million/ $\mu \mathrm{L}$ ) & $4.92( \pm 0.48)$ & $5.00( \pm 0.13)$ & 0.855 \\
\hline Hemoglobin & $14.30( \pm 1.21)$ & $14.70( \pm 0.71)$ & 1.000 \\
\hline Hematocrit (\%) & $42.90( \pm 3.06)$ & $41.80( \pm 1.37)$ & 0.944 \\
\hline Mean corpuscular volume (fL) & $84.90( \pm 4.89)$ & $84.90( \pm 2.42)$ & 0.944 \\
\hline
\end{tabular}

Gamma-GT - Gamma-glutamyltransferase. Gender: OR $(95 \% \mathrm{Cl})=4.71$ (0.76 - 28.05). Skin color: Native American and Asian were excluded from statistical analysis because the sample size were below $5 ;$ OR $(95 \%)=9.02(1.54$ a 97.77$)$.

CAs have a direct association with malignancy. An induced chromosomal instability could also predispose cells to further mutations and by that to an increased risk of malignant transformation [24]. Several researchers studying acute exposure of workers to fuel or organic solvents reported gaps and chromosomal breaks as the chromosomal abnormalities most often detected [16]. While chromosomal translocations were described as markers of chronic exposure that dating back up several years of benzene exposure, so the number of translocations may be a parameter for long term exposure to benzene or BTX $[15,25,26]$. Thus, the elevated involvement of chromosomal translocations found in this study should be most likely due to the long years of workers exposure. Also, chromosome breaks detected in conventional cytogenetic studies cannot be detected in FISH (own unpublished data).

It is worth remembering that significant decreases of WBC, RBC and platelet counts already been observed in human populations exposed to high levels of benzene $[11,27]$. However, we did not find a relationship between the frequency of CAs and the rates of WBC or RBC counts in the studied population. The presence of isolated thrombocytopenia is a change which was previously described in literature [28]. Remarkably, the statistical positivity association of platelet decreased counting with frequency of CAs was closer. Further and longer studies are needed to associate the effects of BTX exposure between frequency of CAs and hematological changes with broad range of exposures. 
In our study a weak association between gender and frequency of CAs were found. It is serious concern the possibility of women's genome be severely more affected by BTX exposure. Several epidemiological studies support the idea that genotoxic and nongenotoxic events following benzene exposure may be initiators of childhood leukemia in utero [1]. Another study on AML have shown that the disease is usually initiated in utero because the leukemic translocations and other genetic changes are present in blood spots collected at birth [29-31]. Thus, mother exposure to benzene could be just as important as childhood exposures in producing childhood AML and acute lymphoblastic leukemia.

\section{Conclusion}

The number of workers with high amount (10/60) and the high frequency of CAs (9.2 per 1,000 metaphase) found shows how necessary it would be to expand this study nationwide, since Brazil has great ethnic and cultural diversity. The results obtained are valuable, but were only obtained from 5 gas stations in Rio de Janeiro city, a pilot study. It is necessary to better understand the risks that these workers are exposed, so that we can be effective in preventing diseases and maintaining the health of these workers and possibly the offspring.

\section{Methods}

This study was approved by the local ethics committee (Instituto Nacional de Câncer - INCA, Brazil). All subjects were informed for each individual about the nature of the study, the potential benefits, and the risks. Participation was voluntary and written informed consent was obtained from each subject before study participation.

\section{Population study}

The study included 50 male and 10 female workers recruited on 6 gas stations, in Rio de Janeiro city. A trained interviewer questioned the members of the study population regarding their age, sex, race, life-style (smoking habits, alcohol and illicit drugs consumption, etc.) and medical and work histories.

Peripheral blood samples were collected for complete hemogram, biochemistry tests and cytogenetics. The cytogenetic analyses were made for delimiting workers at risk and for allowing associations between the frequency of $\mathrm{CA}$ and clinical characteristics.

\section{Chromosome preparation}

Blood samples, $2 \mathrm{ml}$ of heparinized whole blood, were collected by venipuncture. For each sample two cultures were performed according standard technique of lymphocyte cultures. Chromosomes were prepared according to standard procedures after 48 hours of cultivation [32].
FISH was done as previously reported [15] using home made wcp probes for chromosomes 1, 2 and 4 [33]. Per gas station worker 100 metaphases should be analyzed; this was possible in 47 cases. In the remainder 13 cases 34 to 97 metaphases were available.

\section{Hematological and biochemistry analysis}

The hematological analysis consisted of complete hemogram measuring of hemoglobin, hematocrit, mean corpuscular volume and white blood cell counts. The biochemistry analysis consisted of measuring gamma glutamyl transpeptidase (Gamma GT), aspartate transaminase (AST), glutamic pyruvic transaminase (TGP), lactate dehydrogenase (LDH), bilirubin, creatinine and c-reactive protein.

All blood tests were analyzed in the central laboratory of INCA, according to standard haematological methods.

\section{Statistical analysis}

Subjects were divided into two groups ( $\leq 10$ chromosomal abnormalities per 1,000 metaphases and $>10$ chromosomal abnormalities per 1000 metaphases) and compared to clinical characteristics (age, time of employment, race, hemoglobin, leukocytes, etc.) by either Mann-Whitney test or chi-square test (if either quantitative or dichotomic variable). The Mann-Whitney test was performed because the variables quantitative did not have a Gaussian distribution in most of situation. For cytogenetic analyses the Chi-Square Goodness-of-Fit test was performed to evaluate statistical differences of chromosomal aberrations distribution among chromosomes 1 , 2 and 4 . For all statistical tests $\mathrm{p}<0.05$ was considered significant. All analyses were carried out using the PASW software (Version 18, Inc., Chicago, IL, USA).

\section{Endnotes}

$\mathrm{a}_{*}$ Osteoarticular is defined as disease relating to, involving, or affecting bones and joints.

\section{Competing interests}

The authors declare that they have no competing interests.

\section{Authors' contributions}

GA, UBO and MHO designed the study and applied for Research Ethics Board approval. MMT and FS recruited the workers. The cytogenetic data were analyzed by NK and FS. LRS analyzed all data. FS prepared the manuscript draft with important intellectual input from TL, GA and MH. All authors approved the final manuscript and had complete access to the study data.

\section{Acknowledgments}

We thank the subjects who volunteered in the study and the workers of the central laboratory of INCA that provided the hemogram.

\section{Grant support}

Programa de Oncobiologia, Rio de Janeiro, Brazil, and Fundação de Amparo à Pesquisa do Estado do Rio de Janeiro Brazil (APQ1 E-26/111.422/2013). 


\section{Author details}

'Departamento de Patologia e Laboratórios, Faculdade de Ciências Médicas, Universidade do Estado do Rio de Janeiro, Rio de Janeiro, Brasil. ${ }^{2}$ Programa de Pós-Graduação em Ciências Médicas, Faculdade de Ciências Médicas, Universidade do Estado do Rio de Janeiro, Rio de Janeiro, Brasil. ${ }^{3}$ Laboratório de Genética Aplicada, Serviço de Hematologia, Instituto Nacional de Câncer, Rio de Janeiro, Brasil. ${ }^{4}$ Unidade Técnica de Exposição Ocupacional, Ambiental e Câncer, Coordenação de Prevenção e Vigilância, Instituto Nacional de Câncer, Rio de Janeiro, Brasil. ${ }^{5}$ Sociedade Brasileira de Oncologia Clínica, Belo Horizonte, Minas Gerais, Brasil. ${ }^{6}$ Jena University Hospital, Institute of Human Genetics, Friedrich Schiller University, Kollegiengasse 10, D-07743 Jena, Germany. ${ }^{7}$ Instituto Nacional de Câncer, Serviço de Hematologia, Laboratório de Genética Aplicada, Pç. da Cruz Vermelha, 23, 6ªndar, 20230-130 Rio de Janeiro, RJ, Brazil.

Received: 28 January 2014 Accepted: 12 February 2014

Published: 27 February 2014

\section{References}

1. Smith MT: Advances in understanding benzene health effects and susceptibility. Ann Rev Pub Health 2010, 31:133-148.

2. Glass DC, Gray CN, Jolley DJ, Gibbons C, Sim MR, Fritschi L, Manuell R: Leukemia risk associated with low-level benzene exposure. Epidemiol 2003, 14(5):569.

3. Beelte S, Haas R, Germing U, Jansing PJ: Paradigm change in the assessment of myeloid and lymphoid neoplasms associated with occupational benzene exposure. Med Klin 1983, 104(3):197.

4. Holecková B, Piesova E, Sivikova K, Dianovskỳ J: Chromosomal aberrations in humans induced by benzene. Ann Agricult Env Med 2004, 11(2):175.

5. Kim SY, Choi JK, Cho YH, Chung EJ, Paek D, Chung HW: Chromosomal aberrations in workers exposed to low levels of benzene: association with genetic polymorphisms. Pharmacogenet Genomics 2004, 14(7):453-463.

6. Ross D: The role of metabolism and specific metabolites in benzene-induced toxicity: evidence and issues. J Toxicol Environment Health 2000 61(5-6):357-372

7. Smith MT: The mechanism of benzene-induced leukemia: a hypothesis and speculations on the causes of leukemia. Environment Health Perspect 1996, 104(Suppl 6):1219.

8. Swaen GM, Van Amelsvoort L, Twisk Jل, Verstraeten E, Slootweg R, Collins Jנ J, Burns CJ: Low level occupational benzene exposure and hematological parameters. Chem Biol Interact 2010, 184(1):94-100.

9. Maffei F, Hrelia P, Angelini S, Carbone F, Barbieri A, Sanguinetti G, Violante FS: Effects of environmental benzene: micronucleus frequencies and haematological values in traffic police working in an urban area. Mutat Research 2005, 583(1):1-11.

10. Ji Z, Weldon RH, Marchetti F, Chen H, Li G, Xing C, Eskenazi B: Comparison of aneuploidies of chromosomes $21, X$, and $Y$ in the blood lymphocytes and sperm of workers exposed to benzene. Environment Molec Mutagen 2012, 53(3):218-226.

11. Qu Q, Shore R, Li G, Jin X, Chi Chen L, Cohen B, Li K: Hematological changes among Chinese workers with a broad range of benzene exposures. Am J Indust Med 2002, 42(4):275-285.

12. Joo WA, Kang MJ, Son WK, Lee DY, Lee E, Kim CW: Monitoring protein expression by proteomics: human plasma exposed to benzene. Proteomics 2003, 3(12):2402-2411.

13. Zhang L, Rothman N, Wang Y, Hayes RB, Yin S, Titenko-Holland N, Dosemeci M, Wang Y, Kolachana P, Xi L, Li G, Smith MT: Benzene increases aneuploidy in the lymphocytes of exposed workers: a comparison of data obtained by fluorescence in situ hybridization in interphase and metaphase cells. Environ Mol Mutagen 1999, 34(4):260-268

14. Liou SH, Lung JC, Chen YH, Yang T, Hsieh LL, Chen CJ, Wu TN: Increased chromosometype chromosome aberration frequencies as biomarkers of cancer risk in a blackfoot endemic area. Cancer Res 1999, 59(1):1481-1484.

15. Verdorfer I, Neubauer S, Letzel S, Angerer J, Arutyunyan R, Martus P, Gebhart $\mathrm{E}$ : Chromosome painting for cytogenetic monitoring of occupationally exposed and non-exposed groups of human individuals. Mutation Res 2001, 491(1):97-109.

16. Gebhart E, Neubauer S, Schmitt G, Birkenhake S, Dunst J: Use of a three-color chromosome in situ suppression technique for the detection of past radiation exposure. Radiation Res 1996, 145(1):47-52.
17. Zhang L, Eastmond DA, Smith MT: The nature of chromosomal aberrations detected in humans exposed to benzene. Crit Rev Toxicol 2002, 32(1):1-42

18. Carere A, Antoccia A, Cimini D, Crebelli R, Degrassi F, Leopardi P, Marcon F, Sgura A, Tanzarella C, Zijno A: Genetic effects of petroleum fuels. II. Analysis of chromosome loss and hyperploidy in peripheral lymphocytes of gasoline station attendants. Environ Mol Mutagen 1998, 32(2):130-138.

19. Santos-Mello R, Cavalcante B: Cytogenetic studies on gas station attendants. Mutat Res 1992, 280(4):285-290.

20. Silva JM, Santos-Mello R: Chromosomal aberrations in lymphocytes from car painters. Mutat Res 1996, 368(1):21-25.

21. Bukvic N, Bavaro P, Elia G, Cassano F, Fanelli M, Guanti G: Sister chromatid exchange (SCE) and micronucleus (MN) frequencies in lymphocytes of gasoline station attendants. Mutat Res 1998, 415(1):25-33.

22. Zhang L, Lan Q, Guo W, Li G, Yang W, Hubbard AE, Smith MT: Use of OctoChrome fluorescence in situ hybridization to detect specific aneuploidy among all 24 chromosomes in benzene-exposed workers. Chem Biol Interact 2005, 153(4):117-122.

23. Wright EG: Inherited and inducible chromosomal instability: a fragile bridge between genome integrity mechanisms and tumourigenesis. J Pathol 1999, 187(1):19-27.

24. Zhang L, Lan Q, Guo W, Hubbard AE, Li G, Rappaport SM, Smith MT: Chromosome-wide aneuploidy study (CWAS) in workers exposed to an established leukemogen, benzene. Carcinogenesis 2011, 32(4):605-612

25. Smerhovsky Z, Landa K, Rössner P, Brabec M, Zudova Z, Hola N, Pokorna Z, Mareckova J, Hurychova D: Risk of cancer in an occupationally exposed cohort with increased level of chromosomal aberrations. Environ Health Perspect 2001, 109(?):41-45.

26. Pressl S, Stephan G: Chromosome translocations detected by fluorescence in situ hybridisation (FISH)-a useful tool in population monitoring? Toxicol Let 1998, 96:189-194.

27. Aksoy M, Ozeris S, Sabuncu H, Yanardag R: Exposure to benzene in Turkey between 1983 and 1985:a hematologic study on 231 workers. Br J Ind Med 1987, 44(11):785-787.

28. Ruiz M, Vassalo J, Souza CAD: Alterações hematológicas em pacientes expostos cronicamente ao benzeno. Rev Saúd Pública 1993, 27(2):145-14130.

29. Greaves MF, Wiemels J: Origins of chromosome translocations in childhood leukaemia. Nat Rev Cancer 2003, 3(9):639-649.

30. McHale CM, Wiemels JL, Zhang L, Ma X, Buffler PA: Prenatal origin of childhood acute myeloid leukemias harboring chromosomal rearrangements $\mathrm{t}(15 ; 17)$ and inv(16). Blood 2013, 101(11):4640-4641.

31. Wiemels JL, Cazzaniga G, Daniotti M, Eden OB, Addison GM: Prenatal origin of acute lymphoblastic leukaemia in children. Lancet 1999, 354(9189):1499-1503.

32. Liehr T, Claussen U: FISH on chromosome preparations of peripheral blood. In FISH-Technology, Springer-labmanual. Edited by Liehr T, Rautenstrauss B. Berlin: Springer; 2002:73-81.

33. Liehr T, Claussen U: Current developments in human molecular cytogenetic techniques. Curr Mol Med 2002, 2(3):283-297.

\section{doi:10.1186/1755-8166-7-15}

Cite this article as: Santiago et al:: Monitoring of gas station attendants exposure to benzene, toluene, xylene (BTX) using three-color chromosome painting. Molecular Cytogenetics 2014 7:15

\section{Submit your next manuscript to BioMed Central and take full advantage of:}

- Convenient online submission

- Thorough peer review

- No space constraints or color figure charges

- Immediate publication on acceptance

- Inclusion in PubMed, CAS, Scopus and Google Scholar

- Research which is freely available for redistribution 